Recorregut de recerca geològica i mineralògica per les comarques de Gúdar - Javalambre, del Maestrazgo i de l'Alt Maestrat: des de Mosqueruela a la Iglesuela del Cid (I'Anglesola) i a Vilafranca del Cid

Josep Maria Mata-Perelló

Joaquim Sanz Balagué

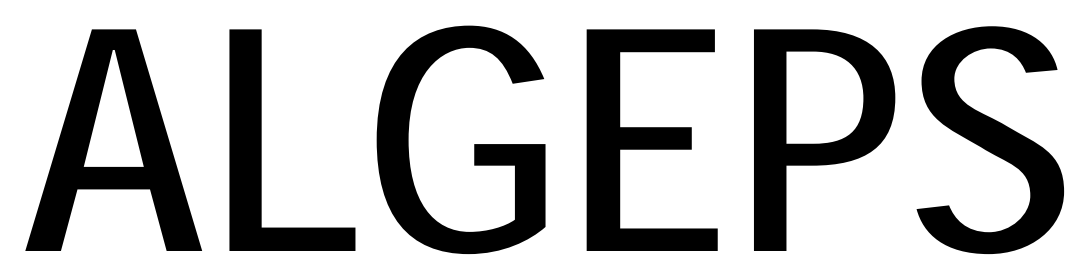

REVISTA DE GEOLOGIA

n. 2

ABRIL 2015 


\title{
RECORREGUT DE RECERCA GEOLÒGICA I MINERALÒGICA PER LES COMARQUES DE GÚDAR - JAVALAMBRE, DEL MAESTRAZGO I DE L'ALT MAESTRAT: DES DE MOSQUERUELA A LA IGLESUELA DEL CID (L“ANGLESOLA) I A VILAFRANCA DEL CID
}

\author{
Josep Maria Mata-Perelló \\ Museu de geologia Valentí Masachs, Escola Politècnica Superior d'Enginyeria de Manresa \\ (EPSEM), Universitat Politècnica de Catalunya · BarcelonaTech (UPC), 08272 Manresa, Spain
}

\section{Joaquim Sanz Balagué}

Departament d'Enginyeria Minera i Recursos Naturals (EMRN), Escola Politècnica Superior d'Enginyeria de Manresa (EPSEM), Universitat Politècnica de Catalunya - BarcelonaTech (UPC), 08272 Manresa, Spain

\section{Paraules clau: Patrimoni geològic i miner; Sistema ibèric; País Valencià}

\begin{abstract}
Resum
Itinerari realitzat el dia 4 de maig del 2014. Aquest itinerari es desenvoluparà íntegrament per una de les unitats geològiques que constitueixen el País Valencià: concretament per la que ocupa la major part de la seva superfície, per la Serralada lbèrica (i dintre d'aquesta pels sectors denominats Muntanyam de Castelló, d'acord amb el treball d'Oriol RIBA (1976).

Igualment, el recorregut s'inclou dintre d'aquesta unitat geològica d'acord amb el treball de GUIMERÀ et altri (1992). També xal dir que per aquests sectors es presenten alineacions clarament ibèriques (NW-SE o WNW-ESE).

Aquest conjunt, es troba constituït majoritàriament per relleus mesozoics (fonamentalment pertanyents al Cretàcic i al Juràssic), de naturalesa calcària, com succeeix al propi cim del Penyagolosa l'indret considerat com al més alt del País Valencià, tot i que el Calderó (situat al Racó d'Ademús, fronterer amb l'Aragó, és uns $50 \mathrm{~m}$ més alt).

Per d'altra banda, aquest recorregut es desenvoluparà a traves de diferents comarques aragoneses $i$ valencianes. Així discorrerà per les comarques de Gúdar - Javalambre $i$ Maeztrazgo; així com per la de l'Alt Maestrat.
\end{abstract}

Algeps. 2015 n.2 Recorregut de recerca geològica i mineralògica per les comarques de Gúdar - Javalambre, del Maestrazgo i de l'Alt Maestrat: des de Mosqueruela a la Iglesuela del Cid (l'Anglesola) i a Vilafranca del Cid 


\section{Objectius fonamentals}

Els objectius que es pretenen assolir, en aquest itinerari, es centraran, fonamentalment, en els següents aspectes:

1.- Estudi dels materials dels afloraments mesozoics (de tots els períodes que el constitueixen, i en especial del Cretàcic i del Juràssic), que constitueixen el Sistema Ibèric, dintre del sector anomenat "Muntanyam de Castelló" (RIBA, 1967).

2.- Observació de l'estructura del Sistema Ibèric (i més concretament del que es troba situat dintre de l'esmentat sector "Muntanyam de Castelló" (RIBA, 1976), que anirem trobant al llarg del recorregut de l'itinerari.

3.- Observació de l'estructura de les alineacions "catalanes", de direcció NNE-SSW (i NE-SW), que trobarem a diferents zones del recorregut, dintre de la denominada Zona d’Enllaç.

4.- Estudi de les mineralitzacions situades al llarg del recorregut. Així, d’acord amb el sentit de la marxa

5.- Observació dels impactes produïts sobre el Medi Natural, com a conseqüència de les explotacions esmentades a l'apartat anterior; i d'altres. I també, si s'escau de les restauracions dutes a terme.

6.- Observació dels indrets relacionats amb el nostre Patrimoni Geològic, que anirem trobant al llarg d'aquest recorregut..

7.- Observació dels indrets relacionats amb el Patrimoni Miner, que anirem trobant al llarg del present itinerari, com és el cas del relacionat amb les diferents explotacions mineres que hem esmentat anteriorment.

\section{Antecedents}

Pel que fa al recorregut de l'itinerari, existeixen solament tres antecedents relatius als itineraris que discorren per aquests indrets. Aquests antecedents son precisament nostres. Es tracta de: MATA-PERELLÓ i MONTANÉ GARCIA (2004a i 2004b); així com de MATA - PERELLÓ et altri (2005).. En tots els casos es tracta d'uns recorreguts molt semblants al del present itinerari, especialment pel que fa als trams finals del mateix, i sobretot pel que fa a la darrera referència bibliogràfica.

Pel que fa a l'estructura geològica de la zona per la qual discorre el recorregut de l'itinerari, ens referirem a dos treballs, sensiblement importants: concretament a GUIMERÀ et altri (1992), i a RIBA et altri (1976). També cal referència dels treballs de l'IGME (1972-1977) i IGME (1986a, 1996b i 1996c), relatius als indrets per on passarà l'itinerari.

I, finalment, pel que fa a la descripció de les mineralitzacions, es referirem a un altres antecedents bibliogràfic mostres. Concretament dels treballs de: MATA-PERELLÓ (1991); i també del treballs del mateix autor (1992a, 1992b, 1992c, 1992d i 1992e) dedicats al inventari mineralògic de les tres comarques (i de les regions a les que pertanyen), per les quals transitarà el recorregut $d^{\prime}$ aquest itinerari.

I, finalment, en relació al Patrimoni Geològic, farem esment del treball aragonès que hem esmentat a l'apartat anterior: DGA (2001).Tots aquests treballs, i d'altres, apareixeran ressenyats a l'apartat dedicat a la bibliografia. 


\section{Recorregut de l'itinerari}

Aquest darrer tram s'iniciarà per les immediacions de Mosqueruela (situada a la comarca de Gúdar - Javalambre). Des d'aquí es sortirà cap a llevant, utilitzant la carretera autonòmica A 1701. Així s'anirà per aquesta carretera cap el poble de la Iglésuela del Cid (I'Anglesola). En aquest recorregut, es faran diverses aturades.

Posteriorment, el recorregut es dirigirà cap el Sud cap a Vilafranca del Cid, utilitzant ara la carretera valenciana CV - 15 (encara que inicialment s'haurà utilitzat també la carretera autonòmica aragonesa $A$ - 227). En aquest tram, també es faran diverses aturades, finalitzant el recorregut a la darrera població esmentada.

\section{Advertiments}

Com en altres recorreguts de RECERCA GEOLÒGICA I MINERALÒGICA ..., si es disposa del temps suficient, poden efectuar-se passant per totes les parades i filloles. En cas contrari, recomanem prescindir de les anomenades PARADES - CONDICIONALS.

També cal tenir en conte que una part del recorregut final de l'itinerari, es realitzarà per camins de terra, per la qual cosa caldrà prendre les degudes precaucions,

Cal tenir, com sempre, una cura molt especial de respecte a la natura, al llarg de tot el recorregut de l'itinerari, i també fora d'ell.

\section{Descripció de l'itinerari}

Com sempre, s'estructurarà en una sèrie de PARADES, que veurem breument a continuació. En cada una de les parades, s'indicarà (entre parèntesi) el número del mapa topogràfic, a escala 1:50.000, on es troba l'aturada.

En aquesta ocasió, totes les aturades es troben situades dintre dels següents fulls del Mapa Topogràfico a Escala 1:50.000 (editat per I'Instituto Geográfico y Catastral de España): 569 (o de Vilafranca del Cid) i 592 (o de Vilahermosa del Río).

Així doncs, la relació ordenada de les aturades que constitueixen aquest itinerari és la següent:

\subsection{Parada 1. Carretera A-1701, entrada a Mosqueruela des de Puertomingalvo, (terme municipal de Mosqueruela, comarca de Gúdar - Javalambre). (Full 592).}

La primera aturada d'aquest itinerari la farem en aquest indret, situat a l'entrada a al poble de Mosqueruela, per la carretera A - 1701, venint des de Puertomingalvo o des de Linares de Mora. Així, aquí, a tocar de les cases del poble, podem fer aquesta primera aturada del present itinerari.

En aquests indrets es troben afloraments dels materials mesozoics que pertanyen al Cretàcic. Es tracta de materials eminentment carbonatats, situats dintre de I'anomenat muntanyam de Castelló RIBA, 1967).

En relació amb aquests materials, cal dir que es troben per arreu moltes formacions kàrtiques. Precisament, en aquest indret on ara ens trobem, es fa pales un interessant poljé. Es tracta 
d'un graó més del conegut interessant Poljé de Mosqueruela, un element molt important del Patrimoni Geològic d’Aragó. (fotografia 1)

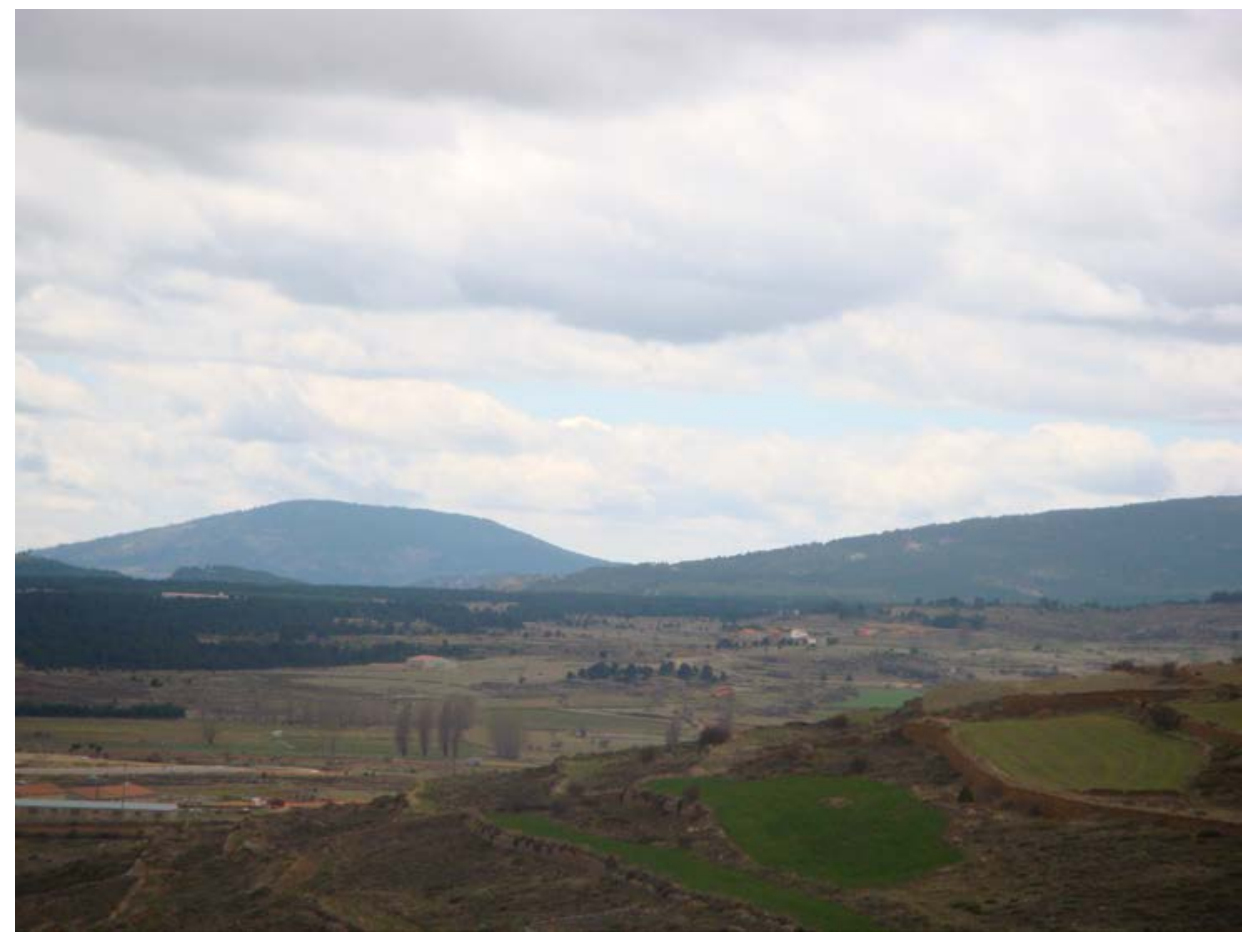

FOTOGRAFIA 1. Un aspecte del Poljé de Mosqueruela

\subsection{Parada 2 - condicional. Poljé del Barranco de Gilbert, (terme municipal de Mosqueruela, comarca de Gúdar - Javalambre). (Full 569).}

Des de la parada anterior, cal sobrepassar totalment el poble de Mosqueruela. Per tal de continuar després cap a la propera població de Vilafranca del Cid, seguint la carretera A - 1701. A uns $2 \mathrm{Km}$ del poble. i a uns $3 \mathrm{Km}$ de la parada anterior (i escaig), caldrà fer la present, si s'escau.

En aquest recorregut, hem continuat trobant els afloraments dels materials esmentats a la parada anterior, de característiques eminentment carbonatades. Aquests materials pertanyen en bona part al Cenomanià.

En aquest indret hi ha un poljé, a la dreta de la carretera, de característiques similars a les del poljé de Mosqueruela, però de dimensions més reduïdes. Cal dir que actualment te un drenatge superficial cap al riu Malo, afluent del riu Montlleó.

\subsection{Parada 3. Carretera a Vilafranca del Cid, Km. 66, (terme municipal de Mosqueruela, comarca del Gúdar - Javalambre). (Full 569).}

Després de fer la parada anterior, cal seguir per la carretera de Vilafranca del Cid, anant cap aquesta darrera població. En arribar a les immediacions del $\mathrm{Km} \mathrm{66}$, caldrà fer una nova aturada, a uns 4-5 $\mathrm{Km}$ de l'anterior. 
En aquest recorregut, hem continuat trobant els materials carbonatats cretàcics. Aquests, en bona part pertanyen al Cenomanià, com ha succeït també als recorreguts que hem fet cap a les dues parades anteriors. En aquest indret, es fa clarament palesa una interferència ibèricacatalana. En efecte, mirant cap al NW es pot veure un anticlinal de direcció ibèrica, amb una sèrie de plecs catalans que l'interfereixen.

\subsection{Parada 4 . Condicional. Carretera a Vilafranca del Cid, $\mathrm{Km} \mathrm{69,} \mathrm{(terme}$ municipal de Mosqueruela, comarca de Gúdar - Javalambre). (Full 569).}

Després de fer la parada anterior, cal continuar una mica més per la carretera que anem seguint i que es dirigeix cap a Vilafranca del Cid. En arribar a les immediacions del Km 69, ens caldrà fer una nova aturada, aproximadament cap a uns $3 \mathrm{Km}$ de I'anterior.

Per d'altra banda, com ha succeït a les parades anteriors, en aquest recorregut que hem fet ara, hem continuat trobant els materials carbonatats cretàcics. També cal dir que aquests, en bona part pertanyen al Cenomanià. En aquest indret, a l'igual que a la parada anterior es fa clarament palesa una interferència ibèrica-catalana. En efecte, mirant ara cap al SE es pot veure un sinclinal de direcció catalana, amb una sèrie de plecs ibèrics que l'interfereixen.

\subsection{Parada 5. Carretera a Vilafranca del Cid, $\mathrm{Km} \mathrm{76,} \mathrm{(terme} \mathrm{municipal} \mathrm{de}$ Mosqueruela, comarca de Gúdar - Javalambre). (Full 569).}

Després de fer la parada anterior, cal continuar una mica més per la carretera que anem seguint i que es dirigeix cap a Vilafranca del Cid. En arribar a les immediacions del Km 76, ens caldrà fer una nova aturada, aproximadament cap a uns $7 \mathrm{Km}$ de I'anterior.

Per d'altra banda, com ha succeït a les parades anteriors, en aquest recorregut que hem fet ara, hem continuat trobant els materials carbonatats cretàcics. També cal dir que aquests, en bona part pertanyen al Cenomanià.

En aquest indret, mirant cap al Sud, es pot veure l'impressionant barranc del Frares, el qual es tributari del riu Montlleó. Des d'aquest lloc, es pot gaudir de l'observació de l'encaixonament dels dos barrancs, com a conseqüència dels esfondraments kàrstics.

\subsection{Parada 6. Carretera a Vilafranca. Immediacions del Navajuelo, trencall del santuari de I’Estrella, (terme municipal de Mosqueruela, comarca de Gúdar - Javalambre). (Full 569).}

Després de fer la parada anterior, es necessari seguir per la carretera, apropant-nos cada vegada més cap a Vilafranca del Cid. En arribar a la cruïlla d'on eix el camí que sén va cap al Santuari de l'Estrella, prop del turó del Navajuelo, caldrà fer una nova aturada. Així, des de la parada anterior haurem recorregut uns $6 \mathrm{Km}$ més.

En aquest recorregut, hem continuat trobant els materials carbonatats cretàcics. Aquests, en bona part pertanyen al Cenomanià, com ha succeït també als recorreguts que hem fet cap a les dues parades anteriors.

En aquest indret, mirant cap a llevant, es fa clarament palès un sinclinal de direcció catalana, per on discorre la carretera, baixant cap a les poblacions de Vilafranca del Cid i cap a la Iglesuela del Cid, per on ara baixarem. Tanmateix es fan paleses una sèrie de plec de direcció ibèrica i altres de direcció catalana, als qual es van interferint. 


\subsection{Parada 7. El Ilosar. Explotació de lloses, (terme municipal de la Iglesuela del Cid, comarca del Maestrazgo). (Full 569).}

Després de fer l'aturada anterior, cal continuar cap a Sant Miquel de la Pobla. En arribar-hi, cal fer una petita fillola, cap a la propera població de la Iglesuela del Cid (cap a I'anomenada "Anglesola"). Aquí es farà una nova aturada, a uns $5 \mathrm{Km}$ de l'anterior.

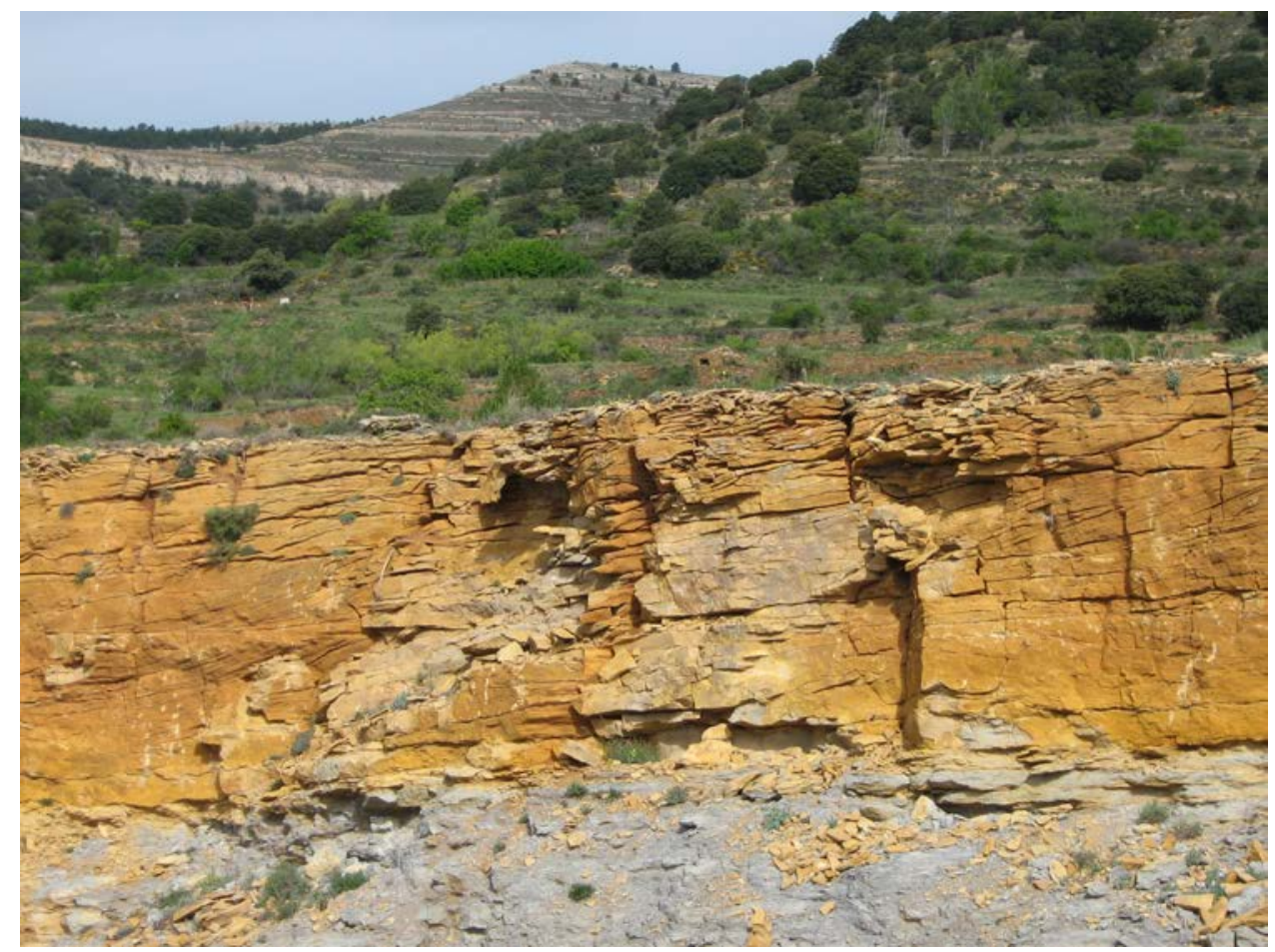

FOTOGRAFIA 2. Petita explotació de llosses

En aquest recorregut, hem anat trobant afloraments dels materials esmentats a la parada anterior, els quals pertanyen al Cretàcic, fonamentalment a l'Aptià.

En aquest indret, hi ha una petita explotació de lloses. Es tracta d'un aflorament explotat de les calcarenites mesozoiques cretàciques de l'Albià. Tot i que es tracta d'una petita explotació en actiu, creiem que la seva rendibilitat és més que dubtosa. FOTOGRAFIA 2.

\subsection{Parada 8 - condicional. Carretera a la Iglesuela del Cid, Km. 65. (La Parreta, terme municipal de Vilafranca del Cid, comarca de l'Alt Maestrat). (Full 569).}

Després de fer l'aturada anterior, cal continuar cal retornar cap a Sant Miquel de la Pobla. En arribar a les immediacions del Km. 65 (de la carretera que se'n va cap a Vilafranca del Cid) ,ens caldrà fer una nova aturada, situada a uns 3’ $5 \mathrm{Km}$ després de l'anterior.

En aquest breu recorregut, efectuat per entre els materials mesozoics del Cretàcic (especialment de l'Albià), els qual formen part del marge occidental de l'Anticlinal de Vilafranca i que es troben a llevant de la fractura esmentada a la parada anterior, de direcció NNW-SSE en tots dos casos. 
En aquest indret hi ha l'aflorament d'un petit "hard-ground". Aquest es localitza entre els materials carbonatats anteriors. Entre els minerals presents en aquest "paleosol", cal fer esment de I'HEMATITES.

\subsection{Parada 9. Entrada a Vilafranca per la carretera a la Iglesuela del Cid. (terme municipal de Vilafranca del Cid, comarca de l'Alt Maestrat). (Full 569).}

Poc després de fer l'aturada anterior, cal anar cap a la població de Vilafranca del Cid. En arribar-hi caldrà fer una nova aturada, a menys de $1 \mathrm{Km}$ de I'anterior

En aquest recorregut, hem anat circulant per entre els materials mesozoics del Cretàcic Inferior, fonamentalment del Barrenià. Tot i això, en aquest lloc es troba el seu contacte amb els també materials cretàcics de l'Albià.

Cal dir que aquest contacte es realitza mitjançant una fractura de direcció NNW-SSE, paral-lela al proper Anticlinal de Vilafranca, situat a ponent d'on ara som.

\subsection{Parada 10. Poligon industrial de Vilafranca del Cid. (terme municipal de Vilafranca del Cid, comarca de l’ Alt Maestrat). (Full 569).}

Poc després de fer l'aturada anterior, cal acabar d'arribar a la població de Vilafranca del Cid. En arribar-hi caldrà anar cap al Sud, per on es troba el Polígon Industrial. En arribar-hi, caldrà seguir fins al Sud, fins arribar a la capçalera del barranc de la Tejeria. En arribar-hi farem una nova aturada, a uns $2 \mathrm{Km}$ de l'anterior.

En aquest recorregut, hem anat circulant per entre els materials mesozoics del Cretàcic Inferior, fonamentalment del Barrenià. Tot i això, en aquest lloc es troba el seu contacte amb els també materials cretàcics de l'Albià.

Des d'aquest indret, es fàcil endevinar que l'esfondrament d'un anterior poljé, ha donat lloc a un conjunt d'abarrancaments, que donen lloc a la coneguda Foz de Vilafranca. (fotografia 3)

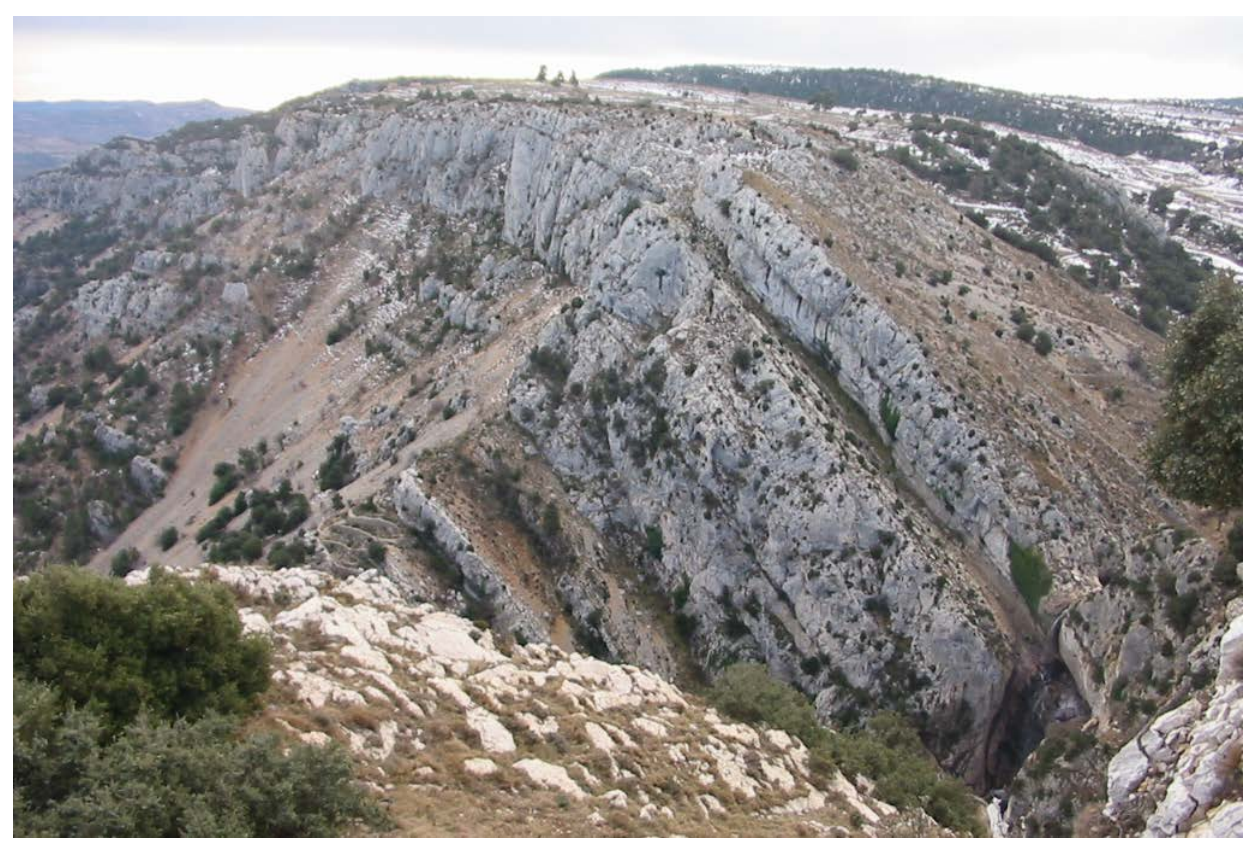

FOTOGRAFIA 3. Un aspecte de la Foz de Vilafranca del Cid

Algeps. 2015 n.2 Recorregut de recerca geològica i mineralògica per les comarques de Gúdar - Javalambre, del Maestrazgo i de l'Alt Maestrat: des de Mosqueruela a la Iglesuela del Cid (l'Anglesola) i a Vilafranca del Cid 
En aquest indret finalitza el recorregut.

\subsection{Bibliografia emprada}

DGA-DDAA (2001).- Puntos de Interés Geológico de Aragón (Diversos Autores). Publicaciones de la Diputación General de Aragón. 242 pag. Zaragoza

GUIMERÀ, J. et altri (1992).- Geologia (II), Història Natural dels Països Catalans, Vol. 2, 547 pàg. Enciclopèdia Catalana, S.A.. Barcelona

IGME (1977).- Mapa Geológico de España a Escala 1:50.000 (Segunda Série-Plan Magna). Explicación de la hoja números: 569 (Mosqueruela). Inst. Geol. Min. España. Ministerio de Industria. Madrid

IGME (1986).- Mapa Geológico de España a Escala 1:200.000. Explicación de la hoja número: 48 / 5-6 (Vinaròs). Inst. Geol. Min. España. Ministerio de Industria. Madrid

IGME (1986b).- Mapa Metalogenético de España a Escala 1:200.000. Explicación de la hoja número: 48 / 5-6 (Vinaròs). Inst. Geol. Min. España. Ministerio de Industria. Madrid

IGME (1986c).- Mapa de Rocas Industriales de España a Escala 1:200.000. Explicación de la hoja número: 48 / 5-6 (Vinaròs). Inst. Geol. Min. España. Ministerio de Industria. Madrid

MATA-PERELLÓ, J.M. (1991).- Inventari de Mineralitzacions i de Minerals del País Valencià. Col•lecció Informe, 546 pag. Manresa

MATA-PERELLÓ, J.M. (1992a).- Les Mineralitzacions de la Comarca de I'Alt Maestrat, revista Algeps, $\mathrm{n}^{\circ} 1,20$ pàgines, Manresa

MATA-PERELLÓ, J.M. (1992b).- Síntesi General de les Mineralitzacions de la Regió de Castelló, revista Algeps, nº 7, 35 pàg. Manresa

MATA-PERELLÓ, J.M. (1992c).- Las Mineralizaciones de la comarca de Gúdar - Javalambre, revista Rodeno, $n^{\circ} .24,30$ pàg. Manresa

MATA-PERELLÓ, J.M. (1992d).- Las Mineralizaciones de la comarca del Maestrazgo, revista Rodeno, $n^{\circ}$. 25, 35 pàg. Manresa

MATA-PERELLÓ, J.M. (1992e).- Síntesis General de las Mineralitzacions de la Región del Bajo Aragón (Sectores Occidentales), revista Rodeno, nº 35, 30 pàg. Manresa

MATA-PERELLÓ, J.M. i MONTANÉ GARCIA, P. (2004a).- Recorregut de recerca geològica i mineralògica per les comarques de l'Alt Maestrat, del Maestrazgo i dels Ports: des de Vilafranca del Cid a Cantavieja, Mosqueruela; i de nou a Vilafranca, cap a Castellfort i Morella. Inèdit, 13 pag. Manresa

MATA-PERELLÓ, J.M. i MONTANÉ GARCÍA, P. (2004b).- Recorregut de recerca geològica i mineralògica per les comarques de la Plana Alta, I'Alcalaten i I'Alt Maestrat: des de la Vall d’Alba i Atzeneta a Vistabella del Maestrat i a Vilafranca del Cid. Inèdit, 13 pag. Manresa

MATA-PERELLÓ, J.M. et altri (2005).- Recorregut de recerca geològica per les comarques de I'Alcalatén, de I'Alt Millars, del Maestrazgo i de l'Alt Maestrat: des de Llucena a Argelita, Lludient, el Castillo de Villamalefa, Villahermosa del Río, Puestomingalvo, Mosqueruela i a Vilafranca del Cid. Inèdit. 26 pàgines. Manresa 